\section{EDUCATION}

Research, Innovation and Solutions on-line
Electronic Journal of Research

in Educational Psychology

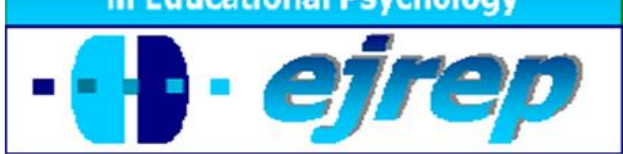

Editorial EOS

\title{
Perceptions of classroom climate and motivation to study English in Saudi Arabia: Developing a questionnaire to measure perceptions and motivation
}

Sena Maherzi

Effat English Academy, Effat University, Jeddah

Saudi Arabia

Correspondence: Dr. Sena Maherzi, Director of Effat English Academy, Effat University, 21478 Jeddah - Saudi Arabia. Email: smaherzi@effatuniversity.edu.sa or maherzi_sena@yahoo.ca

(C) Education \& Psychology I+D+i and Editorial EOS (Spain) 


\begin{abstract}
Introduction. This study describes Effat University students' perceptions of their classroom climate and their motivation to study English, and investigates the validity and reliability of an Arabic questionnaire for measuring student perceptions and motivation.

Method. To this end, 137 female students participated in the cross-cultural validation of this questionnaire, which is comprised of their motivation for studying English, their perceptions of the teacher's communication style and feedback, and their perceptions of autonomy (selfdetermination) and competence.
\end{abstract}

Results. Results provide support for the validity and reliability of the questionnaire.

Discussion and conclusion. Implications for the use of this questionnaire in theoretical and applied research, as well as for teaching with references to perceptions of classroom climate and motivation, are discussed.

Keywords: Students' perceptions, Foreign language learning motivation, Classroom climate, English, Self-determination theory, Cognitive evaluation theory, Cross-cultural validation. 


\section{Percepciones del clima escolar y la motivación de estudiar el inglés en Arabia Saudí. Elaboración de un cuestionario para medir percepciones y motivación.}

\section{Resumen}

Introducción. Este estudio describe las percepciones de las estudiantes de la Universidad de Effat, del clima en el aula y su motivación para estudiar Inglés. Investiga la validez y fiabilidad de un cuestionario de árabe para la medición de percepciones de los estudiantes y la motivación.

Método. Con este fin, 137 estudiantes participaron en la validación transcultural de este cuestionario, que se compone de su motivación para el estudio de Inglés, su percepción de estilo de comunicación del profsor y la retroalimentación, así como la percepción de la autonomía (autodeterminación) y de la competencia.

Resultados. Los resultados proporcionan apoyo a la validez y fiabilidad del cuestionario.

Discusión y conclusiones. Se discuten las implicaciones para el uso de este cuestionario en la investigación teórica y aplicada, así como para la enseñanza, con referencias a la percepción de clima en el aula y la motivación, se discuten.

Palabras clave: Percepciones de los estudiantes, la motivación de aprendizaje de lenguas extranjeras, el clima en el aula, Inglés, teoría de la autodeterminación, la teoría cognitiva de evaluación, la validación intercultural. 


\section{Introduction}

\section{Motivation and Second / Foreign Language Learning}

Most of the studies on motivation and second language (L2) learning (see Au, 1988; Gardner \& Lambert, 1972) were conducted in American and Canadian bilingual contexts, and aimed at testing Gardner's $(1979,1983,1985)^{\mathrm{i}}$ hypothesis of the relationship between integrative motivation (a desire to learn the L2 in order to interact and identify with members from the L2 community, Gardner \& Lambert, 1972), and performance in L2. However, the equivocal findings (cf. Au, 1988; Gardner \& Lambert, 1972), particularly other reasons mentioned by Canadians and non-Canadians (Clément \& Kruidenier, 1983; Dörnyei, 1990; Gardner \& Santos, 1970; Kraemer, 1993; Lukmani, 1972; Lyzack et al., 1976; Oller et al., 1977; Wong, 1982), and the importance of the context where the L2 is learned (Dörnyei, 1990; Kraemer, 1993), lead to a shift in interest from the integrative motivation ('orientation') to other motivational paradigms for understanding language learning motivation, namely the classroom environment (Dörnyei, 2003; Fisher and Reid, 2008; Maherzi, 2000; Noels et al., 1999; Reeve \& Hyungshim, 2005; Telli et al., 2007).

For example, and of particular relevance to the present study, Dörnyei $(1990,2003)^{\mathrm{ii}}$ and Maherzi (2000) argue that studying a L2 in a bilingual context is different from a monolingual one, i.e. where there is no contact with the L2 community and thus no possibility to interact or completely identify with it (as suggested by Gardner's model). Both also maintain that because in this context, the second language is mainly learned as a school subject [or a university course, as is the case for Saudi learners], the identification "can be generalized to the cultural and intellectual values associated with the language, as well as to the L2 itself' (Dörnyei, 2003, p. 6). This is in line with Maherzi's (2000) findings of an integrative reason (e.g. the desire to interact with the English-speaking community), among Tunisian high school students of English, who may have never or scarcely been in direct contact with a native speaker of English, nor travelled to an English-speaking country. Thus, Dörnyei (1994) suggests a three-level conceptual model (see Maherzi, 2000 for a detailed description), comprising of other motivators listed by several scholars, i.e. reasons in line with actual psychoeducational research on classroom dynamics. This model proposes three levels of motivation in foreign language (FL) learning contexts. The first level corresponds to the 'language' and 
includes the community that speaks it, the culture associated to it, and the utility that is linked to developing a competence in it. This motivational dimension is related to Gardner's 'integrative motivation' and 'instrumental motivation'.

The second level corresponds to the 'learner', i.e. his cognitive and affective tendencies that form his relatively stable personality traits. The third level of FL motivation corresponds to the 'learning situation level', itself composed of intrinsic and extrinsic motivation (Deci \& Ryan, 1985), as well as three motivational conditions. The first condition includes 'course-specific motivational components' (Keller, 1983), i.e., lesson plan, material and learning activities that are characterized in terms of 'interest', 'relevance', 'expectancy', and 'satisfaction' (Crookes \& Schmidt, 1991). The second condition includes 'teacher-specific motivational components' consisting of 'authority type' (Deci \& Ryan, 1985), and 'direct socialization of motivation' (Brophy \& Kher, 1986), itself including 'task presentation', and 'feedback' (Brophy \& Good, 1986). The third condition comprises of 'group-specific motivational components', i.e. 'goal-orientedness', 'norm and reward system', 'group cohesion' (Forsyth, 1990) and 'classroom goal structure' (Ames, 1984, 1992; McGroarty, 1993).

Although the above-mentioned motivational paradigms have reoriented research on motivation in L2 / FL contexts, a few scholars have empirically tested their theoretical tenets. These scholars have for example applied Deci and Ryan's (1985) self-determination theory to the study of motivation in the general classroom setting (Deci \& Ryan, 1980, 1985; Harackievicz \& Larson, 1986; Jang, 2008; Murcia et al., 2008; Vallerand \& Reid, 1988; Pelletier et al., 1988; Pelletier, 1992; Vallerand et al., 1992; Vallerand et al., 1993; Reeve \& Deci, 1996; Reeve, 2002), and the L2 classroom setting (Noels et al., 1999; 2000; 2001; Noels, 2001).

Two studies are reported to have applied self-determination theory in a FL language classroom. The first one (Pae, 2008), examined how motivation is associated with selfconfidence and achievement in English as a L2 / FL, among South Korean students. The second one (Maherzi, 2000), mainly based on Dörnyei's (1994) model of FL learning motivation (i.e., teacher's authority type and feedback), and Deci and Ryan's (1985) cognitive evaluation theory, examined the relationship between Tunisian high school students' perceptions of their classroom environment (i.e., teacher's communication style and feedback) ${ }^{\mathrm{iii}}$, and their motivation (Deci \& Ryan, 1985; Vallerand, Blais, Brière and Pelletier, 1989) ${ }^{\text {iv }}$ to study English as a foreign language. 
Hence, one purpose of the present study is to replicate it in another FL context (The Middle East, e.g. Saudi Arabia) ${ }^{\mathrm{v}}$, by examining the link between Effat University students' perceptions of their classroom climate and their motivation ${ }^{1}$ to study English. The Saudi English as a FL context as well as the different types of motivation proposed by Deci and Ryan's self-determination framework (and by Vallerand and his colleagues), namely one of its mini theories, social cognitive theory (CET), which maintains a relationship between these types and perceptions of classroom climate are presented below. Several researchers (e.g. Deci \& Ryan, 2008; Maherzi 2000, Noels et al., 1999) have shown that these paradigms hold potential for practical applications, e.g. enhancing students' intrinsic motivation to study English, namely to improve their skills in this language, as well as future research directions.

\section{Saudi Arabia's English as a Foreign Language Learning Context}

Considered as an instrumental medium of learning at the various stages in the Saudi educational system, English was introduced by the government shortly after the establishment of the Kingdom in 1932, so that citizens learned how to communicate with the outside world (Al-Seghayer, 2005). It then became the only foreign language taught as a subject with instructional objectives and syllabi in 1960 for the secondary level and 1984 for intermediate ones (grades 7, 8, and 9). Now it is a required subject for grades 7 through 12, and students have four 45-minute periods (four hours) weekly. Although the Ministry of Education decided to implement the English curriculum at the elementary level beginning 2002-2003, to improve Saudi students' proficiency level, English is still introduced only in grade 7, compared to being a required subject for $\mathrm{KG}$ levels through grade 12, in both Saudi private schools and international schools.

Moreover, as Al-Seghayer (2005) reports, while focusing on the four skills (listening, speaking, reading, and writing), the objective of teaching English is to provide pupils with enough knowledge that would help them 'in their chosen vocations and introduce them to the outside world' (p. 128). Hence, like Dörnyei (2003) argued (see above, p. 3), English is taught for cultural and intellectual awareness. Upon completion of secondary school, Saudi students

\footnotetext{
1 Motivation refers to the internal or external forces that produce initiation, direction, intensity, and persistence of an individual's behavior (Vallerand \& Thill, 1993).
} 
pursue undergraduates studies in local universities (e.g. Effat University), private colleges, or abroad.

Self-determination Theory: Different Types of Motivation (Deci \& Ryan, 1985, 2000; Ryan and Deci, 2000; Vallerand, Blais, Brière \& Pelletier, 1989)

Self-determination theory (SDT) is a theory of human motivation according to which human beings have natural tendencies to actively engage within their social context, and it focuses on the degree to which their behaviours are volitional or self-determined, i.e. performed freely and under no external influence or interference. Through a process called organismic integration, based on Deci and Ryan's (1985) organismic integration theory or OIT (subtheory of SDT), people are assumed to be active organisms with innate tendencies toward psychological growth and development, who strive to master ougoing challenges and to integrate their experiences into a coherent sense of self, in order to fulfill their needs of competence and self-determination. This natural tendency toward active involvement and psychological growth requires ongoing support from the social context to operate effectively, and thus this context can either support or hinder it (see Maherzi, 2000 for a detailed discussion on both theories).

Deci and Ryan $(1985,1991)$ have proposed different types of motivation that can be ordered along a continuum according to their degree of autonomy or self-determination. From the lowest degree to the highest one, these three types are: amotivation, extrinsic motivation, and intrinsic motivation. Amotivation corresponds to absence of motivation (extrinsic or intrinsic). Deci \& Ryan $(1985,1991)$ contend that individuals are amotivated when they do not perceive a contingency between their behavior (e.g. effort) and its desired outcome. On the contrary, they tend to believe that their behavior is caused by forces out of their control. Moreover, amotivated individuals tend to experience feelings of incompetence, i.e. they feel incapable of reaching the desired outcome, tend to ask themselves why they are doing an activity, and may eventually stop doing it. For example, amotivated Saudi students would ask themselves why they are studying English, as they see no link between their efforts and the desired outcome, e.g. improving their competence in this language. They tend to perceive this improvement as the cause of forces out of their control, and tend to feel incompetent, i.e. incapable of reaching this desired goal. 
Extrinsic motivation corresponds to the accomplishment of a behavior as a means to and not for its own sake, for example to satisfy external demand (e.g., obtaining a reward or avoiding punishment). Deci \& Ryan (1985) and Deci et al. (1991) propose four types of extrinsic motivation, according to their degree of internalization by the self (or selfdetermination). The least self-determined form of extrinsic motivation is external regulation, and corresponds to the accomplishment of a task in order to get a reward (e.g. teacher's praise), or to avoid punishment (confronting peers, etc.). In context of FL learning, the Saudi student who studies English to get a good grade or a good job later on, or to avoid parental confrontation, would be externally regulated.

Introjected regulation is characterized by the internalization or acceptance of external rules or demands ('internal coercion'), which pressure one to behave (Deci et al., 1991). Although within the person, this regulation is not part of the integrated self because it is a response to external contingency (e.g. feeling guilty or ashamed). Examples of this type or regulation are the Saudi student who studies English in order to avoid feeling guilty in case he or she does not speak it well, or to impress his or her friends ('self-aggrandize'). Identified regulation corresponds to a slightly more self-determined form, as the individual tends to identify with external pressure and accomplishes a task more willingly and for personal reasons. Deci et al. (1991) provide the example of the student who spends extra hours studying mathematics because he or she thinks it is important to succeed at this subject. However, this motivation is extrinsic because the student studies not because he or she is interested in mathematics but to arrive at some instrumental goal (improving or succeeding) at it. The source of regulation is thus external to the studying per se. In a FL context, the Saudi students who study English in order to succeed at it, or to increase their GPA, are motivated by introjected regulation. The most self-determined form of extrinsic motivation (and is frequent among adults), is integrated regulation ${ }^{\mathrm{vi}}$ which corresponds to the performance of an activity because it is valued and judged important by the individual, as well as chosen by him or her. The Saudi student who is motivated by integrated regulation would choose to study English because it is important for him or her to do so.

Intrinsic motivation (IM) is the most highly self-determined type of motivation. Intrinsically motivated individuals accomplish a task freely and willingly, for the inherent pleasure and interest experienced in doing it, and without any external coercion (Deci \& Ryan, 1985; Ryan \& Stiller, 1991). Deci and Ryan contend that IM emanates from human psychological 
needs for competence and for autonomy or self-determination. An example of this type of motivation is the Saudi student who experiences pleasure and satisfaction when he or she grasps the meaning of a difficult English word. Vallerand (1997) and Vallerand et al. (1989, 1992; 1993) propose a tripartite taxonomy of IM into more specific motives: IM to know, IM to accomplish, and IM to experience stimulation. An individual is intrinsically motivated to know when he or she performs a task (e.g. reads a book), for the pleasure and satisfaction derived from learning something new; for example, the Saudi FL student who studies English for the joy and pleasure of learning about the FL community. An individual displays intrinsic motivation to accomplish when he or she engages in an activity for the pleasure and satisfaction of attempting to create something or to master a challenge, or to surpass himself or herself. The Saudi FL student who experiences joy and pleasure when he or she is working on a challenging assignment (a project, a difficult exercise, etc.), is intrinsically motivated to accomplish. Finally, an individual who performs a task in order to experience sensory pleasure, aesthetic experience, as well as fun and joy derived from performing it, is intrinsically motivated to experience stimulation. For example, the Saudi FL student who studies English to experience the excitement of participating in a class debate, or for the excitement of speaking this language, displays intrinsic motivation to experience stimulation.

Perceptions of Classroom Environment and Motivation to Study English as a Foreign Language: Cognitive Evaluation Theory (Deci \& Ryan, 1985, 1897, 1991)

As mentioned above, self-determination theory (SDT) contends that individuals have inborn tendencies to grow and develop psychologically, master challenges in the environment, and integrate experience into their self-concept, in order to fulfill their basic psychological needs for competence and autonomy. The fulfillment of these needs depends on the nature of the social context which may either support it or hinder it. In addition, Cognitive Evaluation Theory (CET), a sub-theory of SDT (Deci \& Ryan, 1985, 1987, 1991; see Maherzi, 2000 for a discussion of its tenets), which looks at the social context's impact on an individual's intrinsic motivation, maintains that these needs are major factors of intrinsic motivation. Therefore the degree to which this context (e.g. rewards, punishments, deadlines, etc.), affects intrinsic motivation depends on whether it supports or thwarts the attainment of the needs. Particularly relevant to the present research which aims at considering the relationships between Effat University students' perceptions of their classroom environment and their motivation to study English, CET studies this link in terms of Perceived locus of Causality (strongly 
impacted by the need for autonomy), Perception of Competence, and evaluation or interpretation of an external event. First, Deci and Ryan $(1985,1987,1991,2000)$ contend that individuals' intrinsic motivation is undermined when an external event prompts a change towards a more external perception of locus of causality (E-PLOC), e.g. it hinders their free choice or autonomy (or self-determination), because it controls their behavior. Conversely, when an external event prompts towards internal perception of locus of causality (I-PLOC), it sustains their autonomy or self-determination, because they feel that they are the initiators and regulators of their behavior, and thus their intrinsic motivation is enhanced. In academic contexts, Deci and Ryan (1991) maintain that contrary to control, sustaining autonomy imply that teachers would offer their students the possibility to make choices, minimizing any pressure to behave in a specific way, and thus encourage initiative.

Second, and based on the individual's need to be competent, i.e. to feel capable to reach desired goals and perform well in any activity (Deci \& Ryan, 1991), Deci and Ryan (1985) maintain that positive feedback that would allow the individual to be competent, without any external coercion, would positively affect his or her intrinsic motivation to accomplish optimally stimulating (moderately difficult) activities. On the contrary, the feeling of incompetence or amotivation (see above), would result for example from constant negative feedback.

Finally, external events that are responsible for initiating and regulating an individual's behaviour would comprise of three aspects: informational, controlling, and amotivating. Individuals' interpretation or cognitive evaluation regarding their degree of salience would lead to changes in their perception of the locus of causality of their behaviour, their competence and consequently their intrinsic motivation (Deci \& Ryan, 1985). Thus, the informational aspect would provide individuals with feedback on their performance that encourages their competent engagement, in a context of autonomy or self-determination.

Empirical evidence on the effect of feedback on students' intrinsic motivation has previously been reported in the general classroom setting, particularly in terms of the nature of feedback. For example, Butler (1987), Harackievicz and Larson (1986), Vallerand and Reid (1988) have respectively studied the impact of feedback given in the form of comments, as opposed to the announcement of the grade, and its perception by students' as controlling or autonomy-supportive. The latter two reported a relationship between feedback and the feeling 
of competence, as well as this feeling and intrinsic motivation, i.e. the more controlling feedback was perceived, the less competent the subject felt, and the less intrinsically motivated he was. In other words, the variable competence acted as a mediator in the link between feedback and intrinsic motivation (as proposed by Deci \& Ryan, 1980; 1985's cognitive evaluation theory). Other studies have focused on students' perceptions of the teachers' feedback and communication style, in the general primary level educational setting (Deci et al., 1981a; 1981b; Ryan \& Grolnick, 1986).

More recently, Vallerand, Pelletier, Blais, Brière, Senecal, and Vallières (1993) have conducted a study on 18-year-old junior college students' perceptions of their classroom climate and their feeling of competence, in order to assess a new measure of motivation in postsecondary education, the AMS (Academic Motivation Scale»), an English version of the EME (Echelle de Motivation en Education), which is based on the tenets of self-determination theory. The questionnaire was composed of seven subscales assessing three types of intrinsic motivation (IM-to know, IM-to accomplish, IM-to experience stimulation), three types of extrinsic motivation (external, introjected, and identified regulation), and amotivation. Vallerand and his colleagues reported positive correlations between feeling of competence and IM to know, to accomplish, and to experience stimulation, as well as identified regulation. However, the feeling of competence negatively correlated with introjected regulation, external regulation, and amotivation. Moreover, Perceptions of the classroom climate as informative were positively associated with the three types of IM and the more self-determined forms of EM, but negatively correlated to amotivation. Thus, a greater sense of being competent was linked with greater feelings of intrinsic motivation (particularly IM-to know), and the most self-determined form of motivation (identified regulation), as well as perceptions of an informative and autonomy-supportive classroom climate.

Other studies have reported similar findings, for example that the social context (e.g. parents, teacher, and the school administration) was related to motivation and to high school drop out (Vallerand, Fortier \& Guay, 1997), or the same context and motivation were linked to school performance (Guay \& Vallerand, 1997). Morever, in both studies the feelings of competence and self-determination mediated this link, i.e. perceptions of the teacher as autonomy-supportive were associated with higher levels of competence and self-determination which in turn were related to more self-determined forms of school motivation (as maintained by Deci \& Ryan, 1985). This mediating role was reported in three settings: general classroom 
(Guay \& Vallerand, 1997; Harachievicz \& Larson, 1986; Reeve \& Deci, 1996; Vallerand and his colleagues, 1997; Vallerand \& Reid, 1988), L2 learning classroom (Noels, 1997; 2001; Noels et al., 1999), and FL learning classroom (Maherzi, 2000).

For example, Noels et al. (1999) have examined university students' perceptions of their teacher's communicative style and their motivation to study French as a L2. These students who were registered in a French immersion course in Ottawa (Canada), completed a questionnaire consisting of several scales among which (and relevant to this study), those designed to measure their perceptions of the language teacher's communicative style and as providing positive feedback, their feeling of autonomy, their feeling of competence (through self-evaluation, Clément, 1988), and their motivation (Vallerand et al., 1989; 1992; 1993; Noels et al., 1997), namely amotivation, three types of extrinsic motivation, and intrinsic motivation. Noels and her colleagues reported positive correlations between students' feeling of competence and their intrinsic motivation, as well as identified regulation (most selfdetermined form of extrinsic motivation), but negative with amotivation. In addition, a negative correlation was reported between the perceptions of the teaching as controlling and intrinsic motivation, as well as introjected and identified regulation, but positive between this perception and amotivation as well as external regulation. More positive correlations were found between students' intrinsic motivation (and identified regulation), and their perceptions of their teacher's feedback as positive, while negative correlations were reported between their perceptions of the teacher as controlling and their feeling of competence, but positive when this feedback was perceived as informational.

These results indicate that the less the teacher is perceived as controlling and his or her feedback as positive, the more the student seems to be intrinsically motivated, and the more he or she feels competent. However, the more his or her communication style and feedback are perceived as controlling and negative, the more the student tends to feel incompetent, and to be externally regulated or amotivated.

Whereas the above mentioned studies have looked at students' perceptions of the classroom climate (i.e., teachers' communicative style and feedback), and their motivation (with the feelings of competence and self-determination being mediators), in general classroom and L2 settings, very little has been done to apply the tenets of self-determination theory 
in FL contexts, particularly in examining the relationship of students' motivation and their teachers' communication style and feedback, or FL classroom climate (but Maherzi, 2000).

Maherzi (2000) examined how high school Tunisian students' perceptions of their English (as a FL) classroom climate are related to their motivation ${ }^{2}$ i.e. reason (Deci \& Ryan, 1985), to study this language. The purpose of her study was two-fold: to develop an Arabic ${ }^{\text {vii }}$ version of a questionnaire that was adapted from Noels, Clément and Pelletier (1999), i.e. translate it using appropriate cross-cultural procedures (Vallerand et al., 1989) ${ }^{\text {viii }}$, and to assess whether previous findings from applying Deci \& Ryan's (1985) self-determination theory in general and L2 classroom settings (see studies above), would be replicated with a population of Tunisian high school students of English as a FL. A total of 928 students (252 for the pretest and 676 for the experimentation), randomly selected from 28 governmental schools completed the Arabic questionnaire comprised of four sections. The first one was made up of seven motivation subscales of four items each assessing the three types of IM (IM to know, to accomplish things, and to experience stimulation), three types of extrinsic motivation (external, introjected, and identified regulation), and amotivation. The second one, of four items, measured their feeling of autonomy or self-determination. The third one measured their perceptions of the English teacher and was made up of 12 items. The four one, of four items, assessed their feeling of competence.

Results from the assessment of the reliability (i.e. internal consistency), and the temporal stability ${ }^{\mathrm{ix}}$ of the motivation subscales showed adequate levels of consistency (.69 to .85 , except for external regulation). In addition, findings from the test-retest (cross-cultural validation) reported correlations higher or close to .60. (Vallerand, 1989), and construct validity (i.e. assessed through correlational analyses among the seven motivation subscales and between these scales and other variables deemed to represent motivational antecedents), was confirmed. Moreover, correlations among the seven motivation subscales to assess the presence of the continuum proposed by Deci and Ryan $(1985,1991)$ confirmed it (see Maherzi, pp.7891). Finally, results from the correlations between the motivation subscales and the hypothesized antecedent variables (perceptions of the classroom climate, feelings of selfdetermination and competence), supported Maherzi's predictions. Perceiving the classroom climate as autonomy supportive was positively associated with the three types of IM and the

\footnotetext{
2 Contrary to Gardner's (1985) soci-educational model under which motivation and orientation are conceptualized as two separate entities, the present study, based on Deci and Ryan's (1985) self-determination theory, contends that both concepts overlap, as suggest ed by Ryan (1995; see also, Noels, 2001 and Pae, 2008).
} 
more self-determined form of EM, but negatively associated with amotivation. In addition, associations between motivation subscales and the feelings of competence and selfdetermination were reported higher than with perceptions of the classroom climate, as predicted. Thus, the hypothesized mediating role of perceived self-autonomy and competence in the association between perceptions of the classroom climate and motivation was supported. That is, perceptions of the classroom climate predicted self-perceptions of autonomy and competence, which in turn predicted motivation.

Thus, Tunisian students' perceptions of their English teacher as autonomy supportive and providing constructive and positive feedback, were associated with higher selfperceptions of autonomy and competence, and with the three types of motivation (IM to know, to accomplish things, and to experience stimulation), or with the more self-determined forms of EM (identified and introjected regulations), in studying English. A different pattern was also reported, such as the more the English teacher was perceived by his or her students as controlling and providing negative feedback (e.g. useless criticisms), the lower their selfperceptions of autonomy and competence, and the more externally regulated or amotivated they felt towards studying this language. Whereas previous research has looked at these associations in a high school English as FL context, no studies to date has examined them in a post-secondary one. Thus, the first goal of this study is to replicate research in Saudi Arabia (see p. 5), by examining how Effat University students' perceptions of their English classroom climate, particularly how their perceptions of their teacher's as autonomy-supportive e.g. providing useful feedback (informational comments or questions that elicit viewpoints) versus controlling (providing useless criticism), are linked to their motivation orientations (intrinsic, extrinsic, or amotivated), for studing English, as well as their performance in that language.

\section{Aims and hypotheses}

The present study aims at 1) considering the relationship between Effat university's students' perceptions of the English classroom climate and their motivation to study this language, and 2) to examine and report on the development process of a Saudi version of the questionnaire in post secondary English as FL context. 
Based on the above considerations, the following hypotheses are proposed.

1. Effat university students' perceptions of their English classroom climate, i.e. their teacher, as autonomy supportive and providing constructive feedback will be (a) positively associated with their tendency to be intrinsically motivated, or motivated by identified regulation, to study this language, and (b) negatively associated with their tendency to be amotivated, or motivated by external, or introjected regulation.

2. Students' self-perceptions of autonomy and competence mediate the abovementioned associations. In other words, (a) the more the classroom climate is perceived by the students as autonomy supportive, the higher their self-perceptions of autonomy and competence in studying English, and (b) the higher their self-perceptions of autonomy and competence, the more the students will be intrinsically motivated (to know, to accomplish things, or to experience stimulation), or motivated by identified regulation, to study English. A reverse pattern will be evident with regard to lower self-perceptions of autonomy and competence, i.e. the perceptions will be associated with the students being amotivated, externally regulated, or motivated by introjected regulation.

\section{Method}

\section{Participants}

The sample who participated in the piloting of the questionnaire included 137 Effat University female students, randomly selected, 60 (44\%) of whom were from Effat English Academy and 77 (56\%) from Effat University. The Academy students had Arabic as their first language and were mainly Saudi (60\%), Palestinian / Lebanese (16\%), or Yemeni (10\%). In addition, they were registered either in Bridge (high beginner level, 52\%), or Gateway (preintermediate level, 48\%). Effat University group was registered in General Education courses, i.e. courses that are required of all students, independently of their majors (Architecture, Business Administration, Computer Science, Early Childhood Education, Electrical \& Computer Engineering, English and Translation, Information Systems, or Psychology). They were Saudi (73\%), Jordanian / Syrian / Palestinian (15\%), or Indian / Pakistani (7.5\%). Their mother tongue was Arabic (88\%) or Urdu (12\%). All students ranged in age from 18 to 25 with a mean of 19.27 years, and the age at which all students started studying English ranged 
between zero (5\%), five (40\%), and 12 (55\%), with a mean of 7.65 years. Testing took place in spring 2009, during class hours.

\section{Procedure}

The students were informed of the goal of the study, e.g., to understand why they were studying English and how they perceived the classroom climate, and that 1) there were no right or wrong answers, 2) their participation was voluntary, and 3) all their answers would be kept confidential. Then, the students completed the questionnaire without a time limit. Moreover, the students were given the choice to complete either the English or Arabic version, to avoid the bias resulting from not understanding the items written in a language that is not their mother tongue (Maherzi, 2000; Oppenheim, 1992; Sudman et Bradburn, 1982). During the completion of the questionnaire, at least three students asked for the meaning of an Arabic word pertaining to the scale that assessed students' perceptions of the classroom climate (item 1). The committee replaced the word with a sentence so that its meaning was clearer to the respondents (Vallerand, 1989). Thus, 'Because I enjoy the feeling of acquiring knowledge about the English-speaking community and their way of life" (IM-to know, item 1), was replaced by 'Because I enjoy the feeling of knowing more about the English-speaking community and their way of life', to keep the same structure as the other items pertaining to this scale.

\section{Materials (See Appendix)}

Based on Maherzi (2000) and Noels et al. (1999), the original questionnaire was composed of four scales (51 randomly ordered items), developed in Arabic and English. The first scale assessed the seven types of motivation (or reasons) to study English (28 items, alpha values ranging from .69 to .81 ), except for the external regulation (.54), but close to .60 (Vallerand, 1989). This scale included four items to measure Amotivation (e.g., 'I don't know why I am studying English'; alpha = .85), four items to assess external regulation (e.g., 'In order to get a more prestigious job later on'; alpha $=.54$ ), four items to assess introjected regulation (e.g., 'Because I would feel ashamed if I couldn't speak English'; alpha = .69), four items to measure identified regulation (e.g., 'Because I choose to be the kind of person who can speak more than one language'; alpha $=.76$ ), four items to assess IM-to know (e.g., 'For the pleasure of knowing more about English literature; alpha $=.77$ ), four items to assess IMto accomplish (e.g., 'For the satisfaction I feel when I understand a reading passage'; alpha = 
.82), and four items to assess IM-to experience stimulation (e.g., 'For the excitement I feel in watching English films'; alpha $=.75)$.

An 'other category, please specify' was added at the end of the motivation scale, in order not to irritate the respondents, in case they felt the choice of answers failed to do justice to their own ideas (Oppenheim, 1992), i.e. they may have other reasons for studying English that are not included in the 28 items. Students were asked to indicate on a 7-point scale anchored at one end by 'completely disagree' to 'completely agree', the extent to which a proposed reason for studying English corresponded with their own, and complete the section entitled 'other, please specify', in case they had another reason for studying English that was not included in the scale. A high score indicated a high correspondence between the proposed reason and the students' reason for studying English.

The second scale measured perceptions of the classroom climate, i.e. the teacher's communication style and feedback. This scale included 15 items, eight of which measured controlling climate (e.g., 'The feedback I get from my professor is useless criticisms'; alpha = $.67)^{3}$, and seven autonomy-supportive climate (e.g., 'My professor encourages group work', alpha $=.67)$. Participants indicated on a 5-point likert scale the extent to which they agreed with the proposed item. A high score indicated a high degree of agreement with this item. The third scale included four items that assessed students' perceptions of self-determination in studying English (e.g., 'If I want to do well in English, it's up to me to do it'; alpha =.84). Participants indicated on a 5-point scale the degree to which they agreed with the proposed items and a high score corresponded to a general feeling of being self-determined in studying English.

The fourth scale included four items that assessed students' perceptions of competence in studying this language (alpha $=.83$ ). Respondents evaluated their reading, writing, listening, and speaking in English on a 5-point Likert scale from 'very bad' to 'very good'. A high score indicated a high degree of competence. Questions on the students' age, their previous school / institution, and their teacher's sex appeared on the last page of the questionnaire to avoid disrupting their willingness to answer (Oppenheim, 2000).

\footnotetext{
3 The items of the controlling climate subscale were analyzed using reverse coding (Maherzi, 2000).
} 
However, discussions with Effat University English and psychology professors, as well as professional translators showed the need to develop a more culturally and linguistically adapted Saudi version in both languages. Several modifications were suggested particularly on the Arabic version, namely the motivation scale (e.g. items 2, 4, 10, 28), perceptions of the classroom climate scale (e.g. items 2, 3, 6, 11), and the instructions, so that the questionnaire be formulated in a language to which post-secondary students can relate (Vallerand, 1989). For example, two professors suggested replacing 'high' in items $2,8,13$, and 23 of the motivation scale ('For the high I feel when hearing foreign languages spoken', item 8) by 'excitement' ('For the excitement I feel when hearing foreign languages spoken'). A description of the cross-validation process of this questionnaire with Cronbach alpha of internal consistency and assessment of its construct validity follow.

\section{Cross-Cultural Validation of the Preliminary Version of the Questionnaire}

Following the modifications, two bilingual professors (one from Effat University and another from Mohamed Al Mana College, Khobar), conducted the back translation ${ }^{\mathrm{x}}$. The first one translated the English version into Arabic and the second translated the obtained Arabic version into English, without looking at the original English version. Both preliminary versions were then evaluated by a committee formed by the two translators, two Effat University Saudi students, an Arabic professor, a Psychology professor, and the author of the original English and Arabic versions. The 51 items that were retained by the committee were those that had been retranslated and had kept the original meaning. Then, the committee prepared the scales format that made them look identical to the ones used in the Tunisian context.

\section{Results}

\section{Cross - cultural validation of the questionnaire}

The purpose of the cross-cultural validation of the questionnaire was to (1) develop an experimental version with adequate psychometric properties and (2) make it a useful tool in FL learning contexts, for example Saudi Arabia. Following Maherzi (2000) and Vallerand et 
al. (1989, 1992, 1993), various statistical analyses were conducted on the motivation scale ${ }^{4}$. First, the internal consistency of the questionnaire was assessed using Cronback alpha. Second, in order to test its construct validity, a series of correlations were conducted among the seven motivation subscales, as well as these scales and other variables deemed to represent motivational antecedents (perceptions of classroom climate, self-perceptions of autonomy and competence), as proposed by Deci and Ryan's (1985) Cognitive evaluation theory 5 .

\section{Reliability}

The internal consistency of the questionnaire was assessed using Cronbach alpha $(\alpha)$. Values appear in Table 1. As can be seen, alpha values ranged from .73 to .80, except for the external regulation which had a value of .65. Thus in general, results show adequate levels of internal consistency. These findings are equivalent to those from previous studies, e.g. Vallerand et al. (1989, values ranging from .76 to .86 , with the exception of identified regulation, .62); Vallerand et al. (1992, values ranging from .83 to .86, except for identified regulation; .62); Vallerand et al. (1993, values ranging from .76 to .86, with the exception of identified egulation; .60); and Noels et al. (2000, values ranging from .75 to .88; except for identified regulation; .67); and Maherzi (2000; values ranging from .62 to .84, with the exception of external regulation; .52). Overall, these subscales appear to display adequate levels of internal consistency.

Table 1. Internal Consistency Values for the Motivation Subscales

\begin{tabular}{ll} 
Motivation subscales & $\alpha$ \\
\hline Amotivation & $.80^{*}$ \\
External regulation & $.65^{*}$ \\
Introjected regulation & $.73^{*}$ \\
Identified regulation & $.78^{*}$ \\
IM to know & $.76^{*}$ \\
IM to accomplish & $.76^{*}$ \\
IM to Experience stimulation & $.75^{*}$ \\
\hline
\end{tabular}

Note: $N=137 ; * \underline{p}<.001$.

\footnotetext{
${ }^{4}$ Factorial analysis that tests the theoretical model, i.e. whether the seven-factor structure corresponding to the seven motivation subscales adequately represents the covariance matrix of the data, was not conducted in the piloting stage $(\mathrm{N}=137)$, as this type of analysis requires a bigger sample, e.g. minimum 280 respondents ( 28 x 10, one respondent by motivation scale item; Maherzi, 2000; Vallerand etal., 1992; $1993)$.

${ }^{5}$ Statistical analyses involving correlations between motivation subscales and motivational consequences (e.g., students' English course grade), as well as self-confidence which was reported to be an important motivation determinant (Pae, 2008), will be conducted with the whole student population of Effat University, as the present paper focused on the cross-cultural validation of the questionnaire.
} 
Correlations among the Seven Motivation Subscales. Pearson correlations were computed among the seven motivation subscales in order to test specific associations between them. For example, the strongest positive correlations were predicted among the three types of IM as they assess the same type of motivation, and 2) these subscales were hypothesized to be ordered along a continuum as proposed by Deci \& Ryan's (1985) self-determination theory, i.e. adjacent subscales (e.g., external and introjected regulation) have the highest positive correlations whereas the ones at the opposite ends of the continuum (e.g., intrinsic motivation and amotivtion) have the most negative correlations. The correlation matrix is displayed below.

Table 2. Pearson Correlations Between the Seven Motivation Subscales (N=137).

\begin{tabular}{|c|c|c|c|c|c|c|c|}
\hline $\begin{array}{l}\text { Motivation } \\
\text { Subscales }\end{array}$ & $\begin{array}{c}\text { Amo- } \\
\text { tiva- } \\
\text { tion }\end{array}$ & $\begin{array}{c}\text { External } \\
\text { regulation }\end{array}$ & $\begin{array}{l}\text { Introjected } \\
\text { Regulation }\end{array}$ & $\begin{array}{l}\text { Identified } \\
\text { regulation }\end{array}$ & $\begin{array}{l}\text { IM to } \\
\text { know }\end{array}$ & $\begin{array}{l}\text { IM to } \\
\text { achieve }\end{array}$ & $\begin{array}{l}\text { IM to experien- } \\
\text { ce stimulation }\end{array}$ \\
\hline Amotivation & & -.22 & -.23 & -.32 & $-.38 *$ & $-.33 *$ & $-.34 *$ \\
\hline External regulation & & & .51 & .44 & .40 & .39 & .50 \\
\hline Introjected regulation & & & & .32 & .29 & .44 & .39 \\
\hline Identified regulation & & & & & .57 & .55 & $.60^{*}$ \\
\hline IM to know & & & & & & $.64 *$ & $.69^{*}$ \\
\hline IM to achieve & & & & & & & .53 \\
\hline IM to exp. stimulation & & & & & & & \\
\hline
\end{tabular}

$* p<.001$.

As can be seen, the expected associations were obtained. The highest and most positive correlations are among the three types of IM (ranging from .64 to .69; $p<.001$ ). These results reproduce findings from earlier studies (Maherzi, 2000; Noels, et al., 1999; Vallerand et al., 1989, 1993). Moreover, subscales at the opposite ends of the continuum have the most negative correlations (e.g., Amotivation and the three types of IM, rs = -.38; -.33; -.34; $\mathrm{p}<$ .001). Although these findings are similar to Vallerand et al. (1989, 1993), some deviations were found, namely with IM to experience stimulation, as it was more strongly associated with external regulation $(r=.50)$ than with introjected regulation $(r=.39)$. As reported by Vallerand et al. (1993), this scale behaves differently than the other IM ones. In sum, these results show the presence of a pattern in line with the self-determination continuum (Deci \& Ryan, 1985). 


\section{Hypotheses}

\section{Correlations between the motivation subscales and motivational antecedents}

Several studies have reported that perceptions of the classroom climate were an important determinant of motivation in general / L2, or FL learning classroom settings (Butler, 1987; Deci et al., 1981; Deci et al., 1981; Guay \& Vallerand, 1997; Maherzi, 2000; Noels, 1997; Noels et al., 1999; Vallerand \& Reid, 1988; Vallerand et al., 1993, 1997). Based on their findings, namely that the more this classroom climate was perceived as autonomysupportive, the more the learner tended to be regulated by the most self-determined forms of extrinsic motivation (e.g., identified regulation), or intrinsically motivated to learn, two hypotheses were proposed (see above). First, Effat university students' perceptions of their English classroom climate (their teacher as being autonomy supportive and providing constructive feedback), were expected to be positively associated with more internally regulated, selfdetermined forms of motivation (identified regulation or intrinsic motivation), to study this language, and negatively associated with amotivation, or more externally regulated, less selfdetermined forms of motivation (external, or introjected regulation).

Second, (a) the more the classroom climate, i.e. the teacher is perceived as autonomy supportive and providing constructive feedback, the higher these students' perceptions of selfdetermination and competence in studying English, and (b) the higher these self-perceptions, the more they would be intrinsically motivated or motivated by the most self-determined forms of extrinsic motivation to study this language. A reverse pattern would be evident with regard to lower self-perceptions of autonomy and competence, such as the students are expected to be amotivated or be more externally regulated, or regulated by less self-determined forms of extrinsic motivation (external and introjected regulation).

To test the first hypothesis, correlations were computed between motivation subscales and the antecedent variables (perceptions of classroom climate, perceptions of selfdetermination and competence). Results appear in table 3 below. 
Table 3. Pearson Correlations Between Motivation Subscales and Antecedent Variables

\begin{tabular}{|c|c|c|c|c|c|c|c|}
\hline & Amotivation & $\begin{array}{l}\text { External } \\
\text { regulation }\end{array}$ & $\begin{array}{l}\text { Introjected } \\
\text { regulation }\end{array}$ & $\begin{array}{l}\text { Identified } \\
\text { Regulation }\end{array}$ & IM to know & $\begin{array}{l}\text { IM to } \\
\text { Accomplish }\end{array}$ & $\begin{array}{l}\text { IM to experience } \\
\text { stimulation }\end{array}$ \\
\hline \multicolumn{8}{|l|}{$\begin{array}{l}\text { Antecedent } \\
\text { Variables }\end{array}$} \\
\hline $\begin{array}{l}\text { Controlling } \\
\text { climate }\end{array}$ & $.28 *$ & .28 & .20 & -.33 & -.32 & -.31 & -.20 \\
\hline $\begin{array}{l}\text { Autonomy } \\
\text { supportive } \\
\text { climate }\end{array}$ & $-.16^{*}$ & $.17 *$ & .23 & $.25^{*}$ & $.30 *$ & $.27^{*}$ & $.29 *$ \\
\hline $\begin{array}{l}\text { Perception of } \\
\text { competence }\end{array}$ & $-.41^{*}$ & $.15^{*}$ & .18 & $.45^{*}$ & $.43^{*}$ & $.44 *$ & $.35^{*}$ \\
\hline $\begin{array}{l}\text { Perceptions of } \\
\text { autonomy }\end{array}$ & $-.20^{*}$ & $.14 *$ & .12 & $.26 *$ & $.28 *$ & $.27 *$ & $.16^{*}$ \\
\hline
\end{tabular}

Note: $N=13 ; * p<.001$.

As presented in table 3, the first hypothesis was supported. Perceptions of the classroom climate as autonomy-supportive were associated positively with the three types of IM ( $\mathrm{r}$ $=.30 ; \mathrm{r}=.27$, and $\mathrm{r}=.29$, respectively), and the more self-determined forms of motivation $(\mathrm{r}$ $=.25)$, but associated negatively with amotivation $(\mathrm{r}=-.16)$. A different pattern was shown, such as perceptions of the classroom climate as controlling (providing feedback in the form of useless criticisms), were positively associated with amotivation $(r=.28)$ and less selfdetermined forms of motivation, e.g. external regulation $(r=.28)$ and introjected regulation $(r$ $=20)$.

To test the second hypothesis, namely sub hypothesis (b), based on previous studies that reported positive associations between feeling of competence and intrinsic motivation (Deci et al., 1981; Guay \& Vallerand, 1997; Maherzi, 2000; Noels, 1997; 2001; Noels et al., 1999; Vallerand et al., 1993; 1997), correlations were first computed between motivation subscales and self-perceptions of autonomy and competence. Results of these correlations, which are presented in Table 2, supported the hypothesis. The more self-determined forms of motivation (three types of IM and identified regulation) were associated positively with perceptions of competence in English $(r=.45, r=.43, r=.44$, and $r=.35$, respectively), but negatively with amotivation $(r=-.41)$ and less self-determined forms of motivation, i.e. external regulation.

A similar pattern was shown for perception of self-determination in studying English, as correlated negatively with amotivation $(r=-.20)$ and positively with all motivation sub- 
scales, the less and the more self-determined types $(r=14, r=12, r=26, r=28, r=27$, and $r$ $=16$, respectively).

To test sub hypothesis (a), correlations were computed between perceptions of the classroom climate and self-perceptions of autonomy and competence in studying English. Results are presented in Table 4 below.

\section{Table 4.Correlations Between Perceptions of Classroom Climate and Self-perceptions of Autonomy and Competence $(\mathrm{N}=137)$.}

\begin{tabular}{lccc}
\hline Perceptions of Classroom Climate & 1 & 2 & 4 \\
\cline { 2 - 4 } 1. Controlling Climate & & .30 & $-.10^{* *}$ \\
2. Autonomy supportive climate & & $.36^{*}$ & $.26^{*}$ \\
Self-Perceptions & & $.33^{*}$ \\
3. Perception of autonomy & & \\
4. Perception of competence & & \\
\hline$* \mathrm{p}<.001 ; * * \mathrm{p}<.05$ & &
\end{tabular}

As shown in table 4, all correlations are positive with the exception of controlling climate and perceived competence $(r=-.10)$. Results from Table 3 and Table 4 show that perceptions of classroom climate had an impact on perceptions of self-determination and competence, which in turn determined the type of motivation. These results replicated past findings (Deci \& Ryan, 1980; 1985; Guay \& Vallerand, 1997; Maherzi, 2000; Noels, 2001; 1997; Vallerand \& Reid, 1988; Vallerand et al., 1997), on the mediating effect of perceptions of self-determination and competence, in the associations between perceptions of classroom climate and motivation ${ }^{6}$.

\section{Discussion and conclusion}

One purpose of the present study was to investigate the reliability and construct validity of a Saudi version of a questionnaire measuring Effat students' perceptions of their classroom climate and their motivation to study English as a foreign language. Results showed that the questionnaire had adequate internal consistency, with alpha values ranging from .73 to .80 , except for the external regulation which had a value of .65 , in line with the previous ver-

\footnotetext{
${ }^{6}$ In order to further test this mediating effect, a path analysis using structural equation modeling will be conducted in the experimentation stage, i.e. using the whole Effat university student population.
} 
sion Tunisian (Maherzi, 2000). The construct validity of the motivation scale was first tested with a series of Pearson correlations among the seven motivation subscales to assess the presence of the continuum proposed by Deci and Ryan (1985, 1991), where adjacent subscales show positive correlations, and the subscales at its opposite ends display the highest levels of negative correlations.

Results similar to previous studies (Maherzi, 2000; Noels, 2000; Vallerand et al., 1993) reported that the three types of IM showed the highest positive correlations among themselves. In addition, adjacent subscales showed higher correlations than subscales farther apart. On the other hand, subscales at the opposite ends of the continuum displayed more negative correlations than intermediate subscales.

Moreover, results from the correlations between the motivation subscales and the hypothesized antecedent variables (perceptions of the classroom climate, self-perceptions of autonomy and competence), supported predictions. Perceiving the classroom climate as autonomy supportive was positively associated with the three types of IM and identified regulation, but negatively associated with amotivation. On the contrary, perceiving the classroom climate as controlling positively correlated with amotivation, or less self-determined forms of motivation. Results also supported the hypothesis of an association between feelings of incompetence and absence of self-determination and less self-determined forms of EM and amotivation (Deci et al. 1981; Guay \& Vallerand, 1997; Maherzi, 2000; Noels, 1997; Noels et al. 1999; Ryan \& Grolnick, 1986; Vallerand et al. 1993; 1997; Vallerand \& Reid, 1984, 1988). Indeed, more self-determined forms of motivation (three types of IM and identified regulation) were positively associated with feelings of competence and self-determination, but negatively with amotivation.

A different pattern was also reported, such as the more the English teacher was perceived by his or her students as controlling and providing negative feedback (e.g. useless criticisms), the lower their self-perceptions of autonomy and competence, and the more externally regulated or amotivated they felt towards studying this language. In sum, results from the cross-cultural validation of the questionnaire provide support for the adequacy of its psychometric properties, as it represents a cross-cultural adaptation of the Tunisian version and therefore a reliable tool that can be used in FL learning contexts like Saudi Arabia. Though the pattern of correlations is not causal and more rigorous experimental designs are necessary, 
these correlations are in line with past research on the relevance of Deci \& Ryan's (1985) self-determination theory, particularly in the association of students' intrinsic motivation with and their perceptions of their teacher's communication style and feedback.

Hence, since Effat students study English as a foreign language (as a subject without regularly interacting with the English-speaking community), their teachers are therefore the primary agents in their learning / studying of this language, it is imperative that these teachers develop in them self-determined forms of motivation (intrinsic motivation), through autonomy-supportive classroom climate, that would enhance their personal initiatives and the sharing of their responsibilities in the way they organize their time and effort in studying English (Maherzi, 2000). In addition, students' competence could be developed through self-regulated efforts (Noels et al., 1999), or the implementation of curricula that promote self-regulated learning (Cohen, 1990). Students' self-perceptions of autonomy and competence could be enhanced by understanding and appreciating their points of view (Reeve, 1996), and avoiding immediate contingencies or announcing the highest and lowest grades (Ames, 1992; Brown, 1994) as students become externally regulated (e.g. grade-oriented), and teacher-dependent. Brown states that teachers' job is not to reward students but to guide and help them discover their potential and be challenged by self-determined goals.

Teachers can implement activities that trigger their students' decision making and critical thinking skills, as well as their creativity in determining how to organize their time and efforts (Brophy, 1987). For example, they could provide students opportunities to participate in experiments, role-playing, simulations, educational games, and creative applications of what is being learned, and provide them opportunities to interact with peers because students enjoy activities that allow interaction with their peers (Murcia, et al., 2008). Such opportunities can include whole class activities through scheduling discussion, debate, role-play, or simulation. In addition, follow-up activities should permit students to work together in pairs or small groups to tutor one another, discuss issues, or suggested their own reading material (i.e., pertaining to their major), that would be shared by peers.

Moreover, Nicholls (1983) suggests sustaining task-involvement in students so that they focus their attention on ways to master tasks in order to 1) gain a sense of competence that will in turn 2) make them find learning meaningful. Finally, because intrinsic motivation (and self-confidence) is reported to be the most important determinant of Korean English as 
foreign language students' achievement, Pae (2008) contends that the implementation in 2000, of a Communicative Language Teaching based English curriculum to the Korean formal elementary and middle schools ${ }^{7}$, may have given more communicative opportunities for Korean learners from earlier ages, and thus increasing their pleasure to study that language. Like past researchers who contend that the enhancement of intrinsic motivation imply creating a social context that satisfies inherent human needs (Deci \& Ryan, 1985, 2002; Deci et al., 1991; Maherzi, 2000; Noels, 2001; Noels et al., 1999), Pae (2008) emphasizes the importance of providing choices, informative feedback, a warm and caring classroom climate, and using interactive activities that meet students' needs, as well as allowing them to participate in curriculum design, from needs assessment to evaluation of the learning process. More studies are however needed on these variables, namely the influence of the home environment (Gottfried et al, 1994; Grolnick \& Ryan, 1989, 1991; Ryan \& Stiller, 1991), the institution's management (Boggiano et al., 1992; Eccles, 1993; Guay \& Vallerand, 1997; Ryan \& Stiller, 1991; Vallerand et al., 1997), and students' gender (Maherzi, 2000; Vallerand et al., 1989, 1993), on their perceptions.

\footnotetext{
${ }^{7}$ The goal of the present researcher is to participate in the Saudi project that was proposed in 2002-2003 and aimed at introducing English in the governmental schools' curriculum, at the elementary and intermediate levels. 


\section{Notes}

\footnotetext{
${ }^{\text {i }}$ See Maherzi (2000) for a discussion on Gardner's (1985) model.
}

ii Dörnyei (1990) reported the results of the 1989 study he conducted on 134 Hungarian adults' motivation to study English, which in Hungary, is considered a foreign language. He listed several reasons: 'instrumentality', 'need for achievement', 'interest' and 'esteem towards languages and foreign cultures', but no respondent mentioned an intention to integrate or identify with the Anglophone community.

iii Contrary to Dörnyei (1994); Noels (1997); Noels, Clément, \& Pelletier (1999), Pelletier (1992); Vallerand, Pelletier, Blais, Brière, Sénécal, \& Vallières (1992); and Vallerand, Pelletier, Blais, Brière, Sénécal, \& Vallières (1993), who separated these variables, Maherzi (2000) included both under 'classroom climate', based on Deci et Ryan's (1985, 1987, 1991) Cognitive Evaluation Theory.

${ }^{\text {iv }}$ Some scholars (e.g. Brok, Levy, Brekelmans, \& Wubbels, 2005), have analyzed students' motivation to study English as a foreign language in other contexts (e.g., Holland), in relation to their teacher's interpersonal behavior with a framework based on Leary's (1957) clinical psychology and communication. However, we believe that the dichotomy of extrinsic / intrinsic motivation and its subdivision into seven types based on Deci and Ryan's (1985) self-determination theory and by Vallerand et al. (1989), offers a wider range of reasons and were measured with questionnaires (e.g. Maherzi, 2000; Noels et al., 1999) that had acceptable reliability and construct validity. Morever, and relevant to this study, STD has since the mid 1980's been considered a sound empirical theory (Deci \& Ryan, 2008), and its application to different areas in social psychology has increased considerably during the last two decades (in general, L2, and FL classroom settings; see Pae, 2008).

${ }^{v}$ Since Saudi students study English in a context similar to the one described by Dörnyei (1990, 2003) and Maherzi (2000), the status of English in Saudi Arabia is hence that of a foreign language. (See discussion on page 5).

${ }^{\text {vi }}$ Integrated regulation was not included in this study (and in several others, e.g. Noels et al., 1999; Pae, 2008) because earlier studies (Vallerand et al., 1989; 1992; 1993), have reported no clear distinction between this form and identified regulation, especially among children and teenagers, or a certain degree of maturity that our sample might not have.

vii Since Tunisian students study English as a school subject, without interacting with native speakers of this language, and being exposed to 300 hours of English, they therefore are unable to understand the English items of the questionnaire, Maherzi asked her respondents to complete an Arabic version of the questionnaire that was first cross-culturally validated (Vallerand, Blais, Brière, \& Pelletier, 1989).

viii The purpose of the cross-validation of the questionnaire was to develop an experimental version with acceptable psychometric properties that make it a useful tool in a FL learning contexts, for example Tunisia.

${ }^{i x}$ To asses the temporal stability of the questionnaire a sample of 126 students (randomly selected from two different high schools), completed it twice over a one-month period (Vallerand, 1989).

${ }^{\mathrm{x}}$ Vallerand (1989) recommends (but not urges), the use of parallel back-translation (i.e. two independent back translation sequences), to avoid biases resulting from the two bilingual translators, only one was done as the original both versions of the questionnaire were already cross-cultured, and did not require major modifications. Nonetheless, it was decided to cross-validate again because some items were modified and needed to be translated. See above. 


\section{References}

Al-Seghayer, K. (2005). Teaching English in the Kingdom of Saudi Arabia: slowly by steadily changing. In Braine, G. (Ed.). Teaching English to the world: History, curriculum, and practice. New Jersey: Routledge.

Ames, C. (1992). Classrooms: Goals, structures, and student motivation. Journal of Educational Psychology $y_{2} 84,3,261-71$.

Arkes, H. R., \& Garske, J. P. (1977). Psychological theories of motivation. Monterey, CA: Brooks / Cole.

Au, S. Y. (1988). A critical appraisal of Gardner's social-psychological theory of L2 learning. Language Learning, 1, 75-100.

Brok, P. den, Levy, J., Brekelmans, M. \& Wubbles, T. (2005). The effect of teacher interpersonal behavior on students' subject-specific motivation. Journal of classroom Interaction, 40 (2), 20-33.

Brophy, J., \& Good, T. L. (1986). Teacher behaviour and student achievement. In M.C. Wittrock (Ed.), Handbook of research on teaching. New York: Macmillan.

Brophy, J., \& N. Kher. (1986). Teacher socialization as a mechanism for developing student motivation to learn. In R. S. Feldman (Ed.), The Social psychology of education: Current research and theory. Cambridge: Cambridge University Press.

Brown, H. D. (1994). Teaching by principles. Englewood Cliffs, NJ: Prentice Hall.

Butler, R. (1987). Task-involving and ego-involving properties of evaluation: Effects of different feedback conditions on motivational perceptions, interest, and performance. Journal of Educational Psychology, 79, 474-82.

Cohen, A.D. (1990). Language Learning: Insights for learners, teachers, and researchers.

Boston: Heinle.

Deci, E. L., Nezlek, J., \& Sheinman, L. (1981a). Characteristics of the rewarder and intrinsic motivation of the rewardee. Journal of Personality and Social Psychology, 40, 1-10.

Deci, E. L., \& Ryan, R. M. (1980). The empirical exploration of intrinsic motivational processes. In L. Berkowitz (Ed.), Advances in experimental social psychology. New York: Academic Press.

Deci, E. L., \& Ryan, R. M. (1985). Intrinsic motivation and self-determination in human behaviour. Rochester, NY: Plenum Press. 
Deci, E. L., \& Ryan, R. M. (1987). The support of autonomy and the control of behaviour. Journal of Personality and Social Psychology, 53, 6, 1024-1037.

Deci, E. L., \& Ryan, R. M. (1991). A motivational approach to the self: Integration in personality. In R. Dienstbier (Ed.) Nebraska Symposium on Motivation: Perspectives on motivation, 38, 237-88.

Deci, E. L., Schwartz, A. J., Sheinman, L., \& Ryan, R. M. (1981b). An instrument to assess adults' orientations toward control versus autonomy with children: Reflections on intrinsic motivation and perceived competence. Journal of Educational Psychology, 73, $642-50$.

Deci, E. \& Ryan, R. (2002), Handbook of self-determination Research. Rochester, N.Y: The University of Rochester Press.

Dörnyei, Z. (1990). Conceptualizing motivation in foreign-language learning. Language Learning, 40, 45-78.

Dörnyei, Z. (1994). Motivation and motivating in the foreign language classroom. The Modern Language Journal, 78, 273-83.

Harter, S. (1982). The perceived competence scale for children. Child Development, 53, 8797.

Jang, H. (2008). Supporting students' motivation, engagement, and learning during an uninteresting activity. Journal of Educational Psychology, 100 (4), 798- 835.

Kamada, L.D. (1987). Intrinsic and extrinsic motivation learning processes: Why Japanese can't speak English. Paper presented at the Japan Association of Language Teachers' International Conference on Language Teaching and Learning. Seirei Gakuen, Hamamatsu, Japan.

Keller, J. M. (1983). Motivational design of instruction. In C. M. Reigeluth (Ed.), Instructional design theories and models: An overview of their current status. Hillsdale, New Jersey: Erlbaum.

Maherzi, S. (2000). Tunisian students' perceptions of the classroom climate and their motivation to study English as a foreign language. Unpublished dissertation. Canada: University of Montreal.

Murcia, J., Roman, M., Galindo, C., Alonso, N., \& Gonzalez-Cutre, D. (2008). Peers' influence on exercise enjoyment: A self-determination theory approach. Journal of Sports Science and Medicine, 7, 23-31. 
Nicholls, J. G. (1983). Conceptions of ability and achievement motivation: A theory and its implications for education. In S. G. Paris, G. M. Olson, \& H. W. Stevenson (Eds.), Learning and motivation in the classroom. Hillsdale, N. J.: Erlbaum.

Noels, K. A. (1997). Motivation and language learning: Linking teachers' interpersonal style with students' intrinsic and extrinsic motivation. Paper presented at the Annual Convention of the Canadian Psychological Association, Toronto, Ontario, Canada.

Noels, K.A. (2001). Learning Spanish as a second language: Learners' orientations and perceptions of their teachers' communication style. Language Learning, 51, 107-144.

Noels, K.A., Clément, R., \& Pelletier, L.G. (2001). Intrinsic, Extrinsic, and Integrative Orientations of French Canadian Learners of English. Canadian Modern Language Review, $57,3,43-71$.

Noels, K.A., Clément, R., \& Pelletier, L.G. (1999). Perceptions of teachers' communicative style and students' intrinsic and extrinsic motivation. Modern Language Journal, 83, 24-51.

Noels, K. A., Pelletier, L.G, Clément, R., \& Vallerand, R. (2000). Why are you learning a second language? Motivational orientations and self-determination theory. Language Learning, 53, 33-64.

Ntoumanis, N. (2005). A prospective study of participation in optional school physical education using a self-determination theory framework. Journal of Educational Psychology, 97, 444-453.

Pae, T. (2008). Second language orientation and self-determination theory: A structural analysis of the factors affecting second language achievement. Journal of Language \& Social Psychology, 27, 5-27.

Pelletier, L. G., Brière, N. B., Blais, M. R., \& Vallerand, R. J. (1988). Persisting vs. dropping out: A test of Deci \& Ryan's theory. Canadian Psychology, 29, 600.

Pelletier, L. G. (1992). L'échelle des perceptions du style interpersonnel. [Perceptions of interpersonal style scale]. Unpublished Manuscript. Canada: University of Ottawa.

Pelletier, L. G., \& Vallerand, R. J. (1996). Supervisors' beliefs and students' intrinsic motivation: A behavioural confirmation analysis. Journal of Personality and Social Psychology, 71, 331-40.

Pelletier, L. G., Tuson, K. .M., \& Haddad, N. K. (1997). Client motivation for therapy scale: A measure of intrinsic motivation, extrinsic motivation and amotivation for therapy. Journal of Personality Assessment, 68, 414-35. 
Reeve, J. (1996). Motivating others: Nurturing inner motivational ressources. Needham Heights, Massachusetts: Allyn \& Bacon

Reeve, J. (2002). Self-determination theory applied to educational settings. In E.L. Deci \& Ryan (Eds.), Handbook of self-determination Research. Rochester, N.Y: The University of Rochester Press.

Ryan, R. M. (1995). Psychological needs and the facilitation of integrative processes. Journal of Personality, 63, 397-427.

Ryan, R. M. (2000). Intrinsic and extrinsic motivations: Classic definition directions. Contemporary Educational Psychology, 2, 1, 54-67.

Ryan, R. M., \& Grolnick, W. (1986). Origins and pawns in the classroom: Self-report and projective assessments of individual differences in children's perceptions. Journal of Personality_and Social Psychology, 50, 550-58.

Sudman, S., \& N. M. Bradburn. (1982). Asking questions: A practical guide to questionnaire design. San Francisco: Jossey-Bass.

Vallerand, R. J. (1989). Vers une méthodologie de validation trans-culturelle de questionnaires psychologiques: implications pour la recherche en langue française. [Toward a methodology of cross-validation of psychological questionnaires: implications for research in French]. Canadian_Psychology, 30, 4, 662-80.

Vallerand, R. J., Blais, M. R., Brière, M. N., \& Pelletier, L. G. (1989). Construction et validation de l'échelle de motivation en éducation (EME). [Construction and validation of the Motivation Toward Education Scale]. Canadian Journal of Behavioural Science, $21,3,323-49$.

Vallerand, R. J., Pelletier, L. G., Blais, M. R., Brière, M. N., Sénécal, C., \& Vallières, E. F. (1992). The academic motivation scale: A measure of intrinsic, extrinsic, and amotivation in education. Educational and Psychological Measurement, 52, 4, 1003-17.

Vallerand, R. J., Pelletier, L. G., Blais, M. R., Brière, M. N., Sénécal, C., \& Vallières, E. F. (1993). On the assessment of intrinsic, extrinsic, and amotivation in education: Evidence on the concurrent and construct validity of the academic motivation scale. $E d u$ cational and Psychological Measurement, 53 (1), 159-72.

Vallerand, R. J., \& E. E. Thill. (1993). Introduction à la psychologie de la motivation. [Introduction to the psychology of motivation]. Canada: Études Vivantes. 
Vallerand, R. J., Fortier, M. S., \& Guay, F. (1997). Self-determination and persistence in a real-life setting: Toward a motivational model of high school dropout. Journal of Personality and Social Psychology, 72, 1161-76. 


\section{Appendix}

\section{Amotivation}

1. I don't know. It is a waste of time.

2. Honestly, I don't know. I have the impression of wasting my time in studying English.

\section{External Regulation}

1. In order to get a more prestigious job later on.

2. In order to get good grades in English.

\section{Introjected Regulation}

1. Because I would feel ashamed if I couldn't write in English.

2. Because I would feel ashamed if I couldn't speak English.

3. Because I would feel guilty if I didn't get good grades in English.

\section{Identified Regulation}

1. Because I choose to be the kind of person who can speak more than one language.

2. Because I think it is important for my personal development.

\section{Intrinsic Motivation - To know}

1. Because I enjoy the feeling of acquiring knowledge about the Anglophone community and their way of life.

2. For the pleasure of learning a new language.

\section{Intrinsic motivation - To accomplish things}

1. For the satisfaction I feel when I understand a reading passage.

2. Learning English is a challenge that I enjoy.

3. For the pleasure I experience when I understand a difficult word in English.

\section{Intrinsic motivation - To experience stimulation}

1. For the passion that I experience while speaking English.

2. For the excitement I feel when hearing foreign languages spoken.

3. For the passion I feel when listening to English songs. 


\section{Controlling / negative feedback}

1. My professor announces the best and worst grades.

2. When my professor gives me back my paper, he / she says: «You will not succeed this way, you should do like this!»

\section{Autonomy - supportive positive feedback}

1. My professor provides constructive feedback on my individual work through comments on papers, oral discussions, etc.

2. When my professor gives me back my paper, he / she says: «Congratulations on your effort!» and provides me with strategies to better my work. 